\title{
Memória traumática e direito à verdade: O legado da ditadura militar no Brasil
}

DOI: $10.15175 / 1984-2503-202012303$

\author{
Maria Beatriz Nader ${ }^{*}$ \\ Ayala Rodrigues Oliveira Pelegrine ${ }^{* *}$
}

\begin{abstract}
Resumo
O presente artigo almeja discutir o longo trajeto jurídico-político brasileiro percorrido até o efetivo comprometimento do Estado nacional com seu dever de memória e seu papel de garantidor do direito à informação, à memória e à verdade no tocante ao legado da ditadura militar. Inicialmente, pretende-se apresentar as dificuldades desse processo imbricadas à Lei de Anistia e à política de silêncio e esquecimento forjada pelas Forças Armadas. Em seguida, almeja-se discutir as permanências da Anistia e dessa política nos primeiros governos democráticos dos anos 1990, além dos avanços limitados que foram possíveis. Por fim, deseja-se demonstrar a transformação no perfil do poder Executivo Federal brasileiro, enquanto ator político, a partir dos governos nos anos 2000, quando o compromisso efetivo com a ruptura da Lei de Anistia e o aprofundamento dos direitos humanos é incorporado pela agenda presidencial. Para isso, o método de abordagem a ser utilizado é o dedutivo, ou não ampliativo, e a metodologia procedimental a histórico-monográfica, que possui como base a técnica da investigação documental e bibliográfica.
\end{abstract}

Palavras-chave: ditadura militar; memória, verdade; dever de memória; direitos humanos.

Memoria traumática y derecho a la verdad: el legado de la dictadura militar en Brasil

\section{Resumen}

El presente artículo pretende analizar la larga trayectoria jurídico-política brasileña recorrida hasta el compromiso efectivo del Estado con su deber de memoria y su papel de garantizador del derecho a la información, a la memoria y a la verdad en lo que respecta al legado de la dictadura militar. En un primer momento, se busca presentar las dificultades de ese proceso imbricadas a la Ley de Amnistía de Brasil y a la política de silencio y olvido forjada por las Fuerzas Armadas del país. Posteriormente, el objetivo es analizar los aspectos de la amnistía y de esa política que perduraron durante los primeros gobiernos democráticos de los años 1990, además de los avances limitados

\footnotetext{
* Pós-doutora em Sociologia Política pela Universidade Estadual do Norte Fluminense - UENF. Professora Titular da Universidade Federal do Espírito Santo - UFES, vinculada ao Programa de Pós-Graduação em História Social das Relações Políticas. E-mail: marxis@terra.com.br. (1) https://orcid.org/0000-0001-7462-7154

** Doutoranda no Programa de Pós-Graduação em História Social das Relações Políticas da Universidade Federal do Espírito Santo - UFES. E-mail: lalapelegrine@gmail.com. (1) https://orcid.org/0000-0001-7351-3825
} 
que fueron posibles. En última instancia, se quiere mostrar la transformación del perfil del poder ejecutivo federal brasileño como actor político a partir de los gobiernos de la década de 2000 , cuando el compromiso efectivo con la ruptura de la Ley de Amnistía y la profundización en los derechos humanos se incorpora a la agenda presidencial. A tal efecto, se emplea un planteamiento deductivo y una metodología procedimental histórico-monográfica basada en la técnica de la investigación documental y bibliográfica.

Palabras clave: dictadura militar, memoria, verdad, deber de memoria, derechos humanos.

\title{
Traumatic memory and the right to the truth: the legacy of the military dictatorship in Brazil
}

\begin{abstract}
The present article seeks to discuss the lengthy trajectory taken by Brazil's political-legal systems leading up to the State's effective commitment to its duty of memory and its role in guaranteeing the right to information, memory, and the truth in terms of the legacy of the military dictatorship. At the outset, it aims to outline the difficulties of the process interlinked with the Amnesty Law and the policy of silence and forgetting forged by the Armed Forces. Next, it aims to discuss the permanent effects of the Amnesty and of the policy on the earliest democratic governments of the 1990s, as well as the limited advances that were possible. Finally, it seeks to demonstrate the transformation to the profile of the Brazilian Federal Executive Power as a political actor, based on the governments of the 2000s, when the effective commitment to the rupture in the Amnesty Law and the deepening of human rights was incorporated into the presidential agenda. To do so, the deductive method is employed alongside the historical monograph strand of procedural methodology, with a basis in the documentary and bibliographical research technique.
\end{abstract}

Keywords: Military dictatorship; memory, truth; right to memory; human rights.

\section{Mémoire traumatique et droit à la vérité : I’héritage de la dictature militaire au Brésil}

\section{Résumé}

Le présent article vise à débattre du long chemin juridico-politique brésilien parcouru jusqu'à l'engagement effectif de l'État à honorer son devoir de mémoire et son rôle de garant du droit à l'information, à la mémoire et à la vérité quant à l'héritage de la dictature militaire. II s'agit d'abord de présenter les difficultés de ce processus, liées qu'elles sont à la Loi d'amnistie et à la politique du silence et de l'oubli adoptée par les Forces armées. Nous souhaitons ensuite débattre des permanences de l'Amnistie et de cette politique lors des premiers gouvernements démocratiques des années 1990, mais également des avancées limitées qui ont pu voir le jour. Nous chercherons enfin à montrer les transformations du profil du Pouvoir exécutif fédéral brésilien en sa qualité d'acteur politique à partir des gouvernements des années 2000 , lorsque l'engagement effectif de rupture avec la Loi d'amnistie et l'approfondissement des droits humains ont été incorporés à l'agenda présidentiel. Nous avons utilisé à cet effet une approche déductive et une méthodologie historico-monographique, toutes deux basées sur des techniques de recherche documentaire et bibliographique.

Mots-clés : Dictature militaire ; mémoire ; vérité ; devoir de mémoire ; droits humains. 


\section{创伤记忆和知情权：巴西军人独裁统治的遗产}

\section{摘要:}

本文旨在讨论巴西人民在争取国家履行其记忆义务以及维护独裁政权受害者的知情权所经历的漫长 的司法与政治斗争。作者首先介绍了这一过程所遭遇的阻力，《大赦法》以及失去政权的军人所采 取的沉默和遗忘对策。然后，讨论了巴西大赦的永久性和它在1990年代第一届民主政府中的地位。 最后，我们展示从2000年以来，巴西工党鲁拉政府开始加速履行国家记忆，维护受害者知情权，通 过 “真相调查委员会”，把打破大赦法和深化人权保障的承诺纳入总统的工作议程。本文所采用的 方法是演绎法，基于文献和调查得出结论。

关键词：军人独裁；记忆；知情权；记忆义务；人权

\section{Introdução}

Uma compreensão historiográfica mais aprofundada da ditadura militar no Brasil (1964-1985) vem sendo recentemente possibilitada após um longo caminho de disputas no cenário jurídico-político do país. Após décadas de sigilo e de controle predominantes, medidas institucionalizadas na esfera do poder Executivo Federal puderam, enfim, sinalizar uma perspectiva favorável em relação à questão da justiça de transição, sobretudo no que tange ao direito à memória e à verdade histórica. Portanto, a incorporação da dupla noção do dever de memória - enquanto dever político (HEYMANN, 2007) e moral (RICOEUR, 2003) - pelo Estado brasileiro é um fenômeno novo.

Enquanto agentes públicos cientes da repercussão dos comportamentos políticos sobre o rumo dos direitos humanos no país, os militares impuseram a confidencialidade e o silêncio como regra sobre os atos praticados durante seus governos e sobre a existência de documentos que os pudessem comprová-los. Desse, esses documentos passaram a configurar arquivos sensíveis (QUADRAT, 2013) ou arquivos de direitos humanos (SANTOS, 2016). São registros escritos, imagéticos e orais que, além de fornecerem subsídios concretos sobre o funcionamento burocrático das instituições ligadas à administração pública do período, contém informações que podem ser usadas na elucidação das violações do Estado militar.

A confidencialidade e o silêncio institucional (BAUER, 2012) foram mantidos mesmo após a chamada transição democrática. Importa ressaltar que, apesar de ter recebido este predicado, a passagem do sistema discricionário para a Nova República fora convencionada unilateralmente entre as elites castrenses e civis. O processo garantiu perdão aos 
crimes cometidos pelos agentes do Estado e impôs uma aparente conciliação entre interesses profundamente antagônicos dos atores históricos envolvidos, através de uma cortina de lentidão, gradualismo e pacifismo. Nessas condições tramadas, o pacto transicional deu origem a uma democracia outorgada (NAPOLITANO, 2014), francamente tutelada pelas Forças Armadas.

Símbolo maior do processo de transição e legislação ainda vigente no Brasil, mesmo quarenta anos após sua outorga, a Lei da Anistia violou e ainda permanece violando o sistema internacional de direitos humanos. Isso porque, em sua essência conciliadora, desconstitui os crimes praticados em nome de motivação política durante o período da ditadura, inclusive por agentes militares. Na versão de Fábio Comparato (2010), a Anistia constitui uma aberração jurídica ao instituir a impunidade e não provocar uma verdadeira ruptura, criando a sensação de que a ditadura é um passado inacabado. Certamente, a Lei beneficiou oposicionistas que não foram condenados por de crimes de terrorismo, assalto, sequestro e atentado pessoal, mas, mais largamente, ela configurou uma autoanistia (FICO, 2012) que consagrou a impunidade dos agentes militares.

O excesso de controle castrense e as deliberações da Lei de Anistia atuaram de modo a estimular o que Paul Ricoeur (2007) denomina "excesso de esquecimento" sobre a ditadura militar. Em outras palavras, semearam as bases para uma política oficial de alheamento e amnésia, que provoca a homogeneização da memória coletiva sobre esse período traumático da história brasileira e favorece a privatização da memória (BAUER, 2012) pelo Estado. É preciso ter em vista que a memória é um meio de significação social e temporal dos indivíduos. Lembrar ou esquecer consiste em alterar os elementos que dão significado e sentido ao futuro, já vez que o que se lembra do passado é fundamental para que possa refletir sobre quem se está no presente, onde se encontra no tempo e o que se quer ser no porvir na qualidade de sociedade.

Destarte, promover o acesso à informação, permitir a irrupção de memórias subterrâneas (POLLAK, 1989) na esfera pública e consolidar uma memória coletiva crítica em relação aos eventos traumáticos experimentados na coletividade são ferramentas que operam como sinais de alerta e ajudam a garantir que experiências semelhantes possam ser evitadas (TORELLY, 2010). Os direitos à transparência e publicidade da informação, à apropriação da própria história e à memória são direitos humanos básicos e primordiais (BATISTA, 2012). É dever do Estado garantir o direito à memória e ao acesso à verdade 
para a construção de uma cultura democrática, bem como sustentar e legitimar reformas políticas e jurídicas que caminhem nesse sentido.

A permanência do silêncio institucional após a transição entravou o processo de amadurecimento da democracia nacional, trazendo à tona um elemento típico da cultura política brasileira, qual seja, a preferência pelas soluções conciliatórias (MOTTA, 2009). Os comportamentos de acomodação e negociação diante dos dilemas políticos, que historicamente marcam a tradição política no Brasil, continuaram a se reproduzir na Nova República e contribuíram diretamente para o atraso no estabelecimento da justiça de transição (CATELA, 2009). Ademais, fomentaram a fabricação de uma mentira organizada (ARENDT, 2013) pelos militares, que instituíram um discurso oficial de falsificação e negação dos eventos históricos.

Esse mecanismo político oportunizou a consolidação de uma memória de enaltecimento dos feitos dos governos militares, que tende a apaziguar as contradições históricas e não reconhecer e ocultar a violência que fora perpetrada pelos agentes do Estado. Foram alicerçados os acontecimentos favoráveis à nação, como o suposto resgate frente à ameaça comunista que assombrava todo o continente e o estabelecimento de um ambiente ordeiro e propício ao desenvolvimento da democracia e do capitalismo nacional. Questões relacionadas às prisões arbitrárias, às perseguições, às torturas, às mortes, à não-identificação das vítimas, à não-localização dos corpos, entre outras violações contra os direitos humanos, foram propositadamente deslembradas, desmemoriadas.

A fusão dos elementos acima expostos certificou que fosse extenso e árduo o percurso até que o monopólio autoritário castrense, o pacto com o silêncio institucional e o comportamento conciliador pudessem ser superados em favor de um real comprometimento do poder Executivo brasileiro com o direito ao acesso aos documentos, à memória e à verdade histórica da ditadura. As idas e vindas desse processo refletem, com precisão, a imbricação que existe entre as decisões políticas contemporâneas e a História do tempo presente, sobretudo aquela que se dedica à investigação de eventos e memórias traumáticas e de crimes contra os direitos humanos.

\section{Primeiros passos: os governos democráticos nos anos 1990}

Nos primeiros governos da Nova República, as disputas pelo monopólio da memória e da verdade histórica da ditadura militar se tornaram cada vez mais explícitas. De um lado do embate, as Forças Armadas saíam em defesa da legitimidade de seus atos políticos, 
endossando a inexistência da prática de violações contra os direitos humanos e, mais ainda, de arquivos que os pudessem provar. Do outro lado, diversos segmentos da sociedade civil, como vítimas, familiares de vítimas e grupos de defesa dos direitos humanos, reivindicavam o direito à verdade. Os historiadores e os jornalistas envolvidos no debate alegavam que os documentos comprobatórios das práticas criminosas não somente existiam, como estavam escondidos pelas Forças Armadas ou por terceiros igualmente comprometidos com as violações. Esses grupos exigiam a abertura dos arquivos da ditadura e a institucionalização do depoimento de torturados e torturadores (ANGELO, 2012).

Os primeiros passos se deram na gestão de Fernando Collor de Mello (1990-1992), o primeiro presidente eleito de forma direta e, posteriormente, afastado por processo de impeachment. A Lei n. 8.159 (BRASIL, 1991), aprovada em sua gestão, dispôs sobre a Política Nacional de Arquivos, assegurando, em seu artigo $22^{\circ}$, pleno direito de acesso a documentos públicos. Como consequência, os acervos das antigas Delegacias de Ordem Política e Social (DOPS) e das Delegacias Especializadas de Ordem Política e Social (DEOPS) dos estados de São Paulo e Rio de Janeiro começaram a ser lentamente liberados para consulta pública. Essa documentação foi catalogada e serviu de fonte para investigações históricas pioneiras no tema, as quais buscaram esclarecer o funcionamento das polícias políticas mais atuantes da ditadura (PIMENTA, 1995; FICO, 2001; FURTADO; RAMALHO, 1997).

$\mathrm{Na}$ administração do presidente Fernando Henrique Cardoso (1995-2003), ocorreram avanços e retrocessos. Uma evolução axiomática foi a deliberação da primeira legislação a reconhecer como mortos os cidadãos desaparecidos durante a ditadura militar, a Lei 9.140 (BRASIL, 1995), chamada de Lei dos Desaparecidos. Dezesseis anos após a Lei de Anistia, foi a primeira alteração institucional e legal nas relações entre Estado e sociedade no tocante às violações do regime militar. Pela primeira vez, o Estado brasileiro assumiu sua responsabilidade nos crimes lesa-humanidade (MEZAROBBA, 2003).

Outro avanço foi a aprovação da Lei n. 9.455 (BRASIL, 1997), a Lei da Tortura. Em seu texto, foram tipificados como crimes de tortura atos como constranger alguém com emprego de violência ou grave ameaça, causando sofrimento físico ou mental para obter informação, declaração ou confissão da vítima ou de terceira pessoa, para provocar ação ou omissão de natureza criminosa ou para discriminar racial ou religiosamente; submeter alguém, sob sua guarda, poder ou autoridade, com emprego de violência ou grave ameaça, a intenso sofrimento físico ou mental, como forma de aplicar castigo ou medida de caráter preventivo. A tortura tornou-se crime inafiançável e insuscetível de anistia. 
Contudo, a eficácia da Lei da Tortura foi alvo de críticas. Ao classificar o crime de tortura como crime comum, e não crime próprio - no sentido da prática perpetrada por agentes do Estado -, sua definição não acompanhou os Tratados Internacionais ratificados pelo Brasil, permitindo certa seletividade nos casos que chegariam à justiça e, sobretudo, na forma como seriam julgados aqueles envolvendo agentes do Estado. Quase vinte anos após a vigência dessa legislação, o estudo desenvolvido por Calderoni e Jesus (2015) revelou que agentes públicos acusados por crime de tortura, no Brasil, têm maior chance de serem absolvidos do que não-agentes públicos - especialmente nos tribunais superiores.

Em 2001, foi criada a Comissão de Anistia, sob coordenação do Ministério da Justiça e com o apoio da Anistia Internacional, a fim de analisar pedidos de anistia política e de reparações econômicas protocoladas por pessoas perseguidas e violadas pelo Estado entre 18 de setembro de 1946 e 05 de outubro de 1988. Conforme dados oficiais, ${ }^{1}$ mais de 75 mil pedidos foram requeridos e cerca 60 mil puderam ser apreciados. É válido registrar que a própria documentação comprobatória reunida pelas vítimas e apresentada à Comissão de Anistia inaugurou um acervo documental de alta valia para a pesquisa historiográfica. Cada processo tornou-se uma espécie de antidossiê, contrapondo os dossiês da espionagem e da polícia política, e dando voz aos que foram espionados e torturados (FICO, 2012).

No mesmo ano de apoio na criação da Comissão de Anistia no Brasil e após mais de 30 anos de observação, registros, campanhas e visitas periódicas ao país, a Anistia Internacional publicou um documento em que ofereceu uma interpretação do cenário político e humanitário brasileiro durante a ditadura militar, pontuando que:

\footnotetext{
De 1964 a 1985 o Brasil foi governado por suas forças militares. Durante esse período foi montado o aparato estatal para repressão sistemática da oposição política. O emprego da tortura pelas forças de segurança era política oficial aprovada e, como tal, sua prática tornou-se institucionalizada. Um exemplo desse fato foi o manual "confidencial" de técnicas de interrogação produzido pelo gabinete central do Ministério do Exército e seu respectivo Centro de Informações (CIEX) em 1971, descoberto mais tarde em um arquivo de segurança da polícia no Estado do Paraná. Disso se conclui que o objetivo de um interrogatório de subversivos não é fornecer dados para a justiça criminal processá-los; seu objetivo real (é) obter o máximo possível de informações. Para conseguir isso será necessário, frequentemente, recorrer a métodos de interrogatório que, legalmente, constituem violência. Durante o regime militar, o recurso à execução extrajudicial e ao desaparecimento, bem como a tortura e maus-tratos, tornou-se prática rotineira entre os agentes do Estado. Consequentemente, os métodos de repressão adotados tornam-se cada vez mais refinados e enraizados entre as forças de segurança (ANISTIA INTERNACIONAL, 2001, p. 8).
}

\footnotetext{
${ }^{1}$ Disponíveis em: http://justica.gov.br/seus-direitos/anistia. Acesso em: 26 dez. 2019.
} 
Da mesma forma, o relatório da Anistia Internacional destacou a persistência da situação de desrespeito aos direitos humanos no Brasil mesmo após a transição democrática, salientando que "dezesseis anos após ter a ditadura militar cedido lugar à democracia presidencial, o uso da tortura e dos maus-tratos continua a ser feito no mesmo grau e permanece geralmente impune" (ANISTIA INTERNACIONAL, 2001, p. 1).

Nas últimas cenas do governo Fernando Henrique Cardoso, a instituição do Decreto 4.553 (BRASIL, 2002) provocou retrocessos no compromisso do Estado com o dever de memória, o direito à verdade histórica da ditadura. As comissões de acesso à informação, antes criadas no bojo da política nacional de arquivos, foram destituídas e novamente foi dado ao Executivo o monopólio das regras de classificação dos acervos públicos. O período de inacessibilidade dos arquivos fora dilatado: os documentos reservados, que antes tinham prazo de cinco anos, passavam a ter dez; os confidenciais subiam de dez para vinte anos; os secretos, de vinte para trinta anos; os ultrassecretos, que tinham prazo inicial de cinquenta anos, poderiam permanecer sigilosos permanentemente.

De modo geral, pouco se avançou no que diz respeito à garantia democrática do direito humano à memória e à verdade na primeira década da Nova República. A fragilidade da transição brasileira era ainda muito evidente na medida que explicitava a continuidade do controle autoritário dos militares nos rumos da vida política do país, mesmo que destituído do controle sobre o aparato institucional em sua forma convencionada. Vitor de Angelo (2012) propõe um balanço pertinente da situação da abertura dos arquivos da ditadura ao observar que o Brasil avançou timidamente nas primeiras décadas da Nova República e que poucos dos atos públicos e dos discursos proferidos pelos líderes políticos no período se traduziram em medidas eficazes.

\section{Avanços possíveis na gestão de Luiz Inácio Lula da Silva}

Gestos mais concretos do Executivo brasileiro em relação ao comprometimento com o dever de memória, o direito ao acesso à informação e à verdade do regime militar se deram a partir da gestão do presidente Luiz Inácio Lula da Silva (2003-2010). A chegada de Lula à presidência impulsionou a esperança de que o país pudesse avançar mais rápido nesse sentido, sobretudo entre os que lutavam pela causa, uma vez que grande parte da elite dirigente de suas duas gestões possuía trajetória política ligada aos movimentos sociais (D'ARAUJO, 2009). Reforçava-se a impressão de que um novo capítulo poderia ser escrito na História nacional. Camargo (2016, p. 261) avalia que: 
A partir da segunda metade dos anos 2000 , inicia-se um cenário no qual a Lei de Anistia passa a ser questionada no âmbito estatal, por atores da sociedade civil e do próprio Estado, abrindo uma perspectiva de "desprivatização" da memória política e de novas iniciativas estatais voltadas ao direito à memória e à verdade.

Uma das primeiras iniciativas do presidente Lula foi a assinatura do Decreto n. 5.301 (BRASIL, 2004), normatizando a divulgação de documentos públicos de interesse particular ou coletivo e instituindo a Comissão de Averiguação e Análise de Informações Sigilosas (CAAIS), para fins de administração dos documentos ultrassecretos do Estado. Em seguida, foi instituída a Lei 11.111 (BRASIL, 2005), estabelecendo, em seu artigo $2^{\circ}$, que "o acesso aos documentos públicos de interesse particular ou de interesse coletivo ou geral será ressalvado exclusivamente nas hipóteses em que o sigilo seja ou permaneça imprescindível à segurança da sociedade e do Estado". O governo também designou a criação de um Grupo de Trabalho com vistas à implantação de um futuro centro de referência para abrigar informações, documentos, objetos artísticos e acervos relacionados às violações dos direitos humanos ocorridas durante a ditadura militar.

No fim do ano de 2004, a imprensa brasileira trazia a público assuntos que tangenciavam o regime militar. Além de despertarem a sociedade civil para o "acerto de contas" com seu passado recente, contribuíram para gerar uma crise política entre o Planalto e as Forças Armadas. Um evento emblemático foi a publicação de fotos que comprovariam os maus-tratos sofridos pelo jornalista Vladimir Herzog nas dependências do II Exército, em São Paulo - depois descobriu-se que se tratava do padre canadense Leopoldo d'Astous, que também fora preso e torturado por suposto envolvimento com a oposição ao regime. Na nota do Centro de comunicação Social do Exército divulgada à imprensa em 18 de outubro de 2004, se observa a reiteração do discurso autoritário e a ausência de qualquer autocrítica em relação à violência instituída pelos governos militares (LEIA..., 19 out. 2004). Ao contrário, fica evidente o comportamento de negação, silêncio e tentativa de apagamento da memória do período:

1. Desde meados da década de 60 até início dos anos 70 ocorreu no Brasil um movimento subversivo, que, atuando a mando de conhecidos centros de irradiação do movimento comunista internacional, pretendia derrubar, pela força, o governo brasileiro legalmente constituído. À época, o Exército brasileiro, obedecendo ao clamor popular, integrou, juntamente com as demais Forças Armadas, a Polícia Federal e as polícias militares e civis estaduais, uma força de pacificação, que logrou retornar o Brasil à normalidade. As medidas tomadas pelas Forças Legais foram uma legítima resposta à violência dos que recusaram o diálogo, optaram pelo radicalismo e pela ilegalidade e tomaram a iniciativa de pegar em armas e desencadear ações criminosas. Dentro dessas medidas, sentiu-se a necessidade da criação de uma estrutura, com vistas a apoiar, em operação e inteligência, as atividades necessárias para desestruturar os movimentos radicais e ilegais. O movimento de 
1964, fruto de clamor popular, criou, sem dúvidas, condições para a construção de um novo Brasil, em ambiente de paz e segurança. Fortaleceu a economia, promoveu fantástica expansão e integração da estrutura produtiva e fomentou mecanismos de proteção e qualificação social. Nesse novo ambiente de amadurecimento político, a estrutura criada tornou-se obsoleta e desnecessária na atual ordem vigente. Dessa forma, e dentro da política de atualização doutrinária da Força Terrestre, no Exército brasileiro não existe nenhuma estrutura que tenha herdado as funções daqueles órgãos.

2. Quanto às mortes que teriam ocorrido durante as operações, o Ministério da Defesa tem, insistentemente, enfatizado que não há documentos históricos que as comprovem, tendo em vista que os registros operacionais e da atividade de inteligência da época foram destruídos em virtude de determinação legal. Tal fato é amparado pela vigência, até 08 de janeiro de 1991, do antigo Regulamento para a Salvaguarda de Assuntos Sigilosos (RSAS), que permitia que qualquer documento sigiloso, após a acurada análise, fosse destruído por ordem da autoridade que o produzira, caso fosse julgado que já tinha cumprido sua finalidade. Depoimentos divulgados pela mídia, de terceiros ou documentos porventura guardados em arquivos pessoais não são de responsabilidade das Forças Armadas.

3. Coerente com seu posicionamento, e cioso de seus deveres constitucionais, o Exército brasileiro, bem como as forças coirmãs, vêm demonstrando total identidade com o espírito da Lei da Anistia, cujo objetivo foi proporcionar ao nosso país um ambiente pacífico e ordeiro, propício para a consolidação da democracia e ao nosso desenvolvimento, livre de ressentimentos e capaz de inibir a reabertura de feridas que precisam ser, definitivamente, cicatrizadas. Por esse motivo considera os fatos como parte da história do Brasil. Mesmo sem qualquer mudança de posicionamento e de convicções em relação ao que aconteceu naquele período histórico, considera ação pequena reavivar revanchismos ou estimular discussões estéreis sobre conjunturas passadas, que a nada conduzem (LEIA..., 19 out. 2004).

Dias depois, mais uma notícia vinha a público: a queima ilícita de documentos sigilosos - muitos dos documentos portavam o carimbo de "confidencial" e "secreto" - das Forças Armadas na base aérea de Salvador (QUEIMA..., 13 dez. 2004). Entre os papéis, havia prontuários, fichas e relatórios produzidos pelos agentes dos órgãos da inteligência do Exército, da Aeronáutica e da Marinha, durante os governos militares, dando conta dos "inimigos políticos" da nação, ou seja, indivíduos relacionados à oposição "terrorista". Novamente, o debate sobre o apagamento da memória do período militar vinha à tona.

Reagindo aos eventos, o ministro-chefe do Gabinete de Segurança Institucional do governo Lula, general Jorge Armando Félix, concedeu uma entrevista a um jornal de circulação nacional. Embora não falasse oficialmente em nome das Forças Armadas, quando indagado sobre a questão da abertura dos arquivos, expôs sua opinião e concedeu à coletividade brasileira uma amostra do pensamento predominante entre o alto escalão militar sobre o assunto:

[...] Félix - É aquela história, não tem nada bonito ali.

Folha - Não tem nada bonito dos dois lados? 
Félix - Não, só tem de um lado. Tomamos todas as precauções, porque ali tratavase de pessoas, e é preciso que se preserve o direito à individualidade, o direito à privacidade. Essas pessoas estão aí, estão vivas.

Folha - E os documentos sobre tortura, desaparecimentos?

Félix - Não encontrei nada na Abin até agora. Há dossiês que nos preocupam porque tratam de pessoas em situações extremamente constrangedoras. Eu até gostaria de destruir esse tipo de documento. Isso não é história, não vai fazer bem a ninguém. Se aparecer, só vai fazer mal à reputação das pessoas, e tem gente aí hoje com 75, 80 anos de idade. Para que serve isso?

[...] Folha - O sr. vê problema em divulgar os arquivos?

Félix - Tem problema divulgar porque ali você fala de pessoas, de indivíduos. Tem gente que naquela época estava na clandestinidade, tinha outra mulher e hoje não tem, está com a antiga. Se isso aparecer, você pode destruir uma família. Tem os companheiros que entregaram, está escrito ali. [...]

Folha - Se houve delação é porque alguém forçou.

Félix - Às vezes, não forçava não. Às vezes, chegava lá e abria tudo. Por medo, né?

Folha - Havia bons motivos para ter medo, não é, general?

Félix - O pior inimigo que você pode ter é o Estado. O Estado é muito poderoso. Não queira ter o Estado como inimigo. Não quero (FÉLIX, 2004, p. 4).

Acontecimentos como esses foram determinantes para que a pressão sobre o Estado brasileiro aumentasse e para que a questão da memória do passado ditatorial e as políticas de direitos humanos relacionadas aos crimes de lesa-humanidade fossem definitivamente incorporadas na agenda nacional. No fim de 2005, o poder Executivo Federal decretou a transferência da custódia definitiva dos acervos de órgãos centrais dos governos militares para o Arquivo Nacional (AN), sob a supervisão da Casa Civil. Seguiram os acervos do Serviço Nacional de Informações (SNI), da Comissão Geral de Informações (CGI) do Conselho de Segurança Nacional (CSN) e da Agência Brasileira de Inteligência (ABIN). Mais tarde, outros fundos documentais foram sendo gradualmente transferidos: da Divisão de Inteligência Policial do Departamento de Polícia Federal (DINPO), do Centro de Informações do Exterior do Ministério das Relações Exteriores (CIEX) e da Comissão Geral de Inquérito Policial-Militar (CGIPM).

O recolhimento dos arquivos junto ao Arquivo Nacional tornou o Brasil detentor de um dos maiores acervos públicos de arquivos sensíveis, antes sigilosos, produzidos por um governo ditatorial. Apesar disso, a questão do acesso integral aos documentos ainda permanecia entravada pelo problema da privacidade. Os acervos cujos documentos continham nomes ou dados pessoais continuavam sob sigilo, dado que a administração do Arquivo Nacional 
temia que a própria instituição fosse alvo de processos judiciais no caso de alguém se sentir exposto ou invadido por conta de sua divulgação. Fico (2012) considera que esse foi um dos grandes equívocos no processo de abertura dos arquivos, provocando inúmeros problemas na efetividade do direito à memória e à verdade, além de ter emperrado a disponibilidade de novas fontes que permitissem o redirecionamento da produção historiográfica.

Outras ações foram se desenvolvendo no âmbito da administração federal. Uma delas foi o Projeto "Direito à memória e à verdade", da Secretaria Especial de Direitos Humanos (SEDH), que resultou na publicação do relatório oficial, chancelado pelo Estado brasileiro, "Direito à Memória e à Verdade - Comissão Especial de Mortos e Desaparecidos", em 2007. Na publicação, eram atribuídos aos agentes públicos da ditadura os crimes de tortura, estupro e outras violações de direitos humanos. No ano de 2008 , foi elaborado o Projeto "Marcas da Memória", da Comissão da Anistia, além da Audiência Pública "Limites e Possibilidades para a Responsabilização Jurídica dos Agentes Violadores de Direitos Humanos durante o Estado de Exceção no Brasil”, promovida pelo Ministério da Justiça e pela Comissão de Anistia, que debateu a interpretação da Lei de Anistia de 1979.

Em maio de 2009, o Presidente da República coordenou o ato de lançamento do projeto Memórias Reveladas - Centro de Referência das Lutas Políticas no Brasil (19641985), sob responsabilidade da Casa Civil. O Memórias Reveladas passou a interligar digitalmente o acervo dos governos militares recolhido ao Arquivo Nacional, a partir de 2005, com vários outros arquivos federais e com arquivos estaduais de quinze unidades da federação. A campanha do projeto, que passou a ser veiculada pelos principais meios de comunicação do país, constituiu um chamamento do governo federal à sociedade para recoIher documentos produzidos ao longo do regime militar, sobretudo os que pudessem ajudar a localizar os mais de 140 desaparecidos políticos do país. No meio acadêmico:

\begin{abstract}
Um exemplo da boa receptividade pode ser conferido na edição do mês de outubro de 2009 da revista Pesquisa FAPESP, publicada pela Fundação de Amparo à Pesquisa do Estado de São Paulo. A reportagem de quatro páginas afirmava que "uma revolução está acontecendo nos arquivos públicos de todo o país desde maio deste ano", em referência ao Banco de Dados Memórias Reveladas que disponibiliza informações e documentos relativos ao período da ditadura militar para consultas online (ANGELO, 2012, p. 200).
\end{abstract}

Atualmente, cerca de 651 mil documentos estão disponíveis para consulta pública em um banco de dados virtual, ${ }^{2}$ enquanto cerca de outros 27 mil permanecem em sigilo.

\footnotetext{
2 Disponível em: <http://base.memoriasreveladas.gov.br/mr/seguranca/Principal.asp>. Acesso em 12 dez. 2019.
} 
São imagens de documentos oficiais, produzidos pelos órgãos responsáveis pela geração das informações que alimentavam a ação repressiva dos governos militares. Também há diversos outros registros, como cartas, mapas, desenhos, fotografias, folhetos e panfletos produzidos por cidadãos que, no exercício de seu direito de livre manifestação contra a ordem política vigente, foram designados inimigos internos e defrontaram-se, conforme a fala do general Jorge Armando Félix, com o "pior inimigo": o Estado.

O Memórias Reveladas se tornou um polo difusor de informações contidas nos registros documentais sobre as lutas políticas no Brasil nas décadas de 1960 a 1980. Cabe mencionar que, para além de permitir o acesso público ao acervo da ditadura e fomentar a pesquisa histórica, o Memórias Reveladas desenvolveu inúmeras iniciativas no sentido de fortalecer as garantias básicas do Estado democrático de direito no Brasil, como chamamentos públicos incentivando a doação de acervos sobre o regime militar, campanhas na mídia para a identificação de desaparecidos políticos, concursos monográficos como forma de estímulo às pesquisas embasadas em fontes documentais do período entre 1964-1985, seminários temáticos, publicações atravessadas pelas questões do acesso à informação, da memória, da democracia e dos direitos humanos.

No final de 2009, foi lançado o Programa Nacional de Direitos Humanos, que trazia como $6^{\circ}$ eixo orientador o Direito à Memória e à Verdade. Eram lançadas três diretrizes no sentido da promoção deste direito: reconhecimento da memória e da verdade como Direito Humano da cidadania e dever do Estado; preservação da memória histórica e construção pública da verdade; e modernização da legislação relacionada com promoção do direito à memória e à verdade, fortalecendo a democracia. No bojo da primeira diretriz, o Programa traçava como objetivo específico promover a apuração e o esclarecimento público das violações de Direitos Humanos praticadas no contexto da repressão política ocorrida no Brasil, no período fixado pelo artigo $8^{\circ}$ do ADCT da Constituição, a fim de efetivar o direito à memória e à verdade histórica e promover a reconciliação nacional. Para tanto, propunha a instituição de uma Comissão Nacional da Verdade para examinar as violações de direitos humanos praticadas no contexto da repressão política no período mencionado.

Os avanços assegurados durante a gestão de Luiz Inácio Lula da Silva em relação à abertura dos arquivos foram irrefragáveis. Medidas como a instituição de Lei mantendo o sigilo dos documentos públicos somente em casos imprescindíveis, relativos à segurança da sociedade e do Estado; a transferência da custódia definitiva dos acervos de órgãos dos governos militares para o Arquivo Nacional; a publicação do relatório "Direito à Memória e 
à Verdade - Comissão Especial de Mortos e Desaparecidos", como os nomes de agentes da ditadura ligados aos crimes contra os direitos humanos; o debate em audiência pública, promovido pelo Ministério da Justiça e pela Comissão de Anistia, sobre a Lei de Anistia, a fundação do Memórias Reveladas; e o lançamento do Programa Nacional de Direitos Humanos, com a indicação de instituição de uma Comissão Nacional da Verdade, transparecem passos largos do Executivo no cumprimento do seu dever de memória e do seu papel de garantidor dos direitos fundamentais.

\section{Lei de Acesso à Informação e Comissão Nacional da Verdade: os êxitos do governo de Dilma Vana Rousseff}

As condições históricas que levaram a uma ruptura mais efetiva no monopólio castrense sobre a memória e a verdade histórica da ditadura - e no estado de divórcio da sociedade brasileira com seu passado traumático (GAGNEBIN, 2010) - se deram durante a gestão da primeira mulher a assumir a presidência da República brasileira, Dilma Vana Rousseff (2011-2016). Ainda no primeiro ano, seu governo aprovou duas medidas, simultâneas e complementares, que simbolizaram divisores de águas nos elementos autoritários e conciliatórios que tradicionalmente compõem o cenário jurídico-político brasileiro. A decretação da Lei $n$. 12.527 (BRASIL, 2011a), a Lei de Acesso à Informação (LAI), e a instituição da Comissão Nacional da Verdade (CNV), pela Lei n. 12.528 (BRASIL, 2011c), representaram uma ambiciosa iniciativa em direção a um governo mais aberto, atuante e responsivo com a verdade, o dever de memória e o espírito democrático que se propõe a ter.

Com a sanção da Lei de Acesso à Informação, o Brasil se tornou o 89a país do mundo a possuir esse tipo de legislação específica (PAES, 2011). Tardiamente, a legislação sintonizou o Brasil com a disposição do artigo $19^{\circ}$ da Declaração Universal de Direitos Humanos: "todo o indivíduo tem direito à liberdade de opinião e de expressão, o que implica o direito de [...] procurar, receber e difundir [...] informações e ideias por qualquer meio de expressão" (ASSEMBLEIA GERAL DA ONU, 1948). A LAI inseriu o país em um panorama internacional de adoção de marcos regulatórios favoráveis à transparência governamental e à promoção dos direitos humanos. Este panorama passou a se firmar, sobretudo, a partir da metade século $X X$, com o amadurecimento das experiências democráticas modernas e o reforço do período histórico que Bobbio (1992) entende como sendo de ampliação do reconhecimento e da proteção dos direitos individuais. 
No cenário político-jurídico, a implantação da Lei de Acesso provocou descontinuidades que refletiram não só no vocabulário, mas na própria percepção sobre as atribuições e os limites de ação estatal. Conforme Giddens (1985/2001), o Estado é uma construção histórica que concentra o poder, o controle social e a memória por meio da centralização de informações, as quais constituem um capital da sociedade sob sua tutela, e não propriedade. No Brasil, o direito de acesso à informação é garantido pela Constituição de 1988, no artigo $5^{\circ}$, inciso XIV: "é assegurado a todos o acesso à informação e resguardado o sigilo da fonte, quando necessário ao exercício profissional" e no artigo $216^{\circ}$, parágrafo $2^{\circ}$ : "cabem à administração pública, na forma da lei, a gestão da documentação governamental e as providências para franquear sua consulta a quantos dela necessitem" (BRASIL, 1988). Na prática, contudo, o que historicamente se reproduzia na arena política brasileira era o abuso do Estado no seu papel de tutor das informações públicas e a negligência do direito de acesso pelos próprios governos democráticos que o instituíram.

Então, além de incluir conceitos inéditos, como transparência pública, gestão pública compartilhada e compromisso com o tratamento, a disponibilidade, a autenticidade e a integridade da informação, a Lei de Acesso à Informação forneceu o amparo regulatório necessário ao cumprimento do dever do Estado previsto na Constituição. A legislação não instituiu uma política nacional de arquivos, mas normatizou o direito ao acesso, dispondo em seu artigo $5^{\circ}$ que a administração deve garantir acesso à informação e franqueá-la mediante procedimentos objetivos e ágeis, de forma transparente, clara e em linguagem de fácil compreensão.

A prescrição fundamental da Lei de Acesso reside na ideia de que qualquer pessoa, física ou jurídica, sem obrigatoriedade de apresentar motivo, possa receber informações dos órgãos e entidades sob a jurisdição do poder público. Para isso, esse direito deve ser garantido conforme os princípios que regem a administração pública e as seguintes diretrizes, firmadas em seu artigo $3^{\circ}$ : a publicidade como regra geral e o sigilo como exceção; a divulgação de informações de interesse público e coletivo independentemente de solicitações; a utilização de meios de comunicação viabilizados pela tecnologia da informação; o fomento ao crescimento da cultura de transparência na administração pública; o estímulo ao desenvolvimento do controle social sobre a administração pública.

A LAI trouxe em seu bojo uma proposta de transformação cultural. Ela previu dispositivos concretos e aplicabilidade prática, comprometendo-se a adotar medidas para garantir a acessibilidade de conteúdo para pessoas com deficiência, a limitar suas exceções, a 
garantir a gratuidade da informação, a divulgar proativamente as informações de interesse coletivo e a estabelecer procedimentos e prazos que facilitem o acesso à informação. Entretanto, é preciso ponderar que, apesar de todos os avanços que propõe, sua eficácia enfrenta alguns desafios impostos pela própria realidade brasileira. Trata-se de uma legislação que supõe uma ordem informacional e jurídica que objetivamente não existe no país, bem como uma participação mais ativa e consciente da sociedade civil no debate de assuntos de interesse geral. Para que o cidadão exercite o direito de acesso, é preciso que ele conheça seus direitos, o que ainda é algo distante na conjuntura nacional. Além disso, não há uma política pública de informações e nem um ente específico para cuidar da revisão de decisões ligadas ao acesso à informação, o que dificulta a efetividade de suas proposições. Ponderando sobre tais desafios, Jardim (2012, p. 18) afirma que:

É uma oportunidade histórica para a sociedade e o Estado brasileiros a aprovação de uma Lei de Acesso à Informação Pública (LAI) após 23 anos de uma Constituição que consagrou os princípios do direito à informação e do dever da administração pública na gestão e acesso a documentos, sucedida por dispositivos legais regulamentadores que jamais foram implementados. Num Estado historicamente autoritário, marcado pela opacidade informacional, inclusive no processo democratizante das últimas décadas, a LAI aponta para diversos desafios na sua implementação. Um desses desafios consiste no fato de que a LAI insere o cidadão no epicentro numa ordenação jurídica à qual não corresponde uma ordenação equivalente no plano informacional. As possibilidades de minimizar essa defasagem entre a LAI (e sua regulamentação e aplicação em diversos setores do Estado) e as condições reais de acesso à informação não estão contempladas no dispositivo legal. [...]

O fato é que, apesar dos entraves em sua aplicabilidade, a Lei de Acesso proporcionou avanços em termos de amadurecimento das garantias democráticas no Brasil. Do ponto de vista historiográfico, também houve um grande impacto. A legislação assegurou a abertura dos arquivos da ditadura militar ao definir que informações e documentos referentes às condutas de violações dos direitos humanos cometidas por agentes públicos, ou a mando de autoridades públicas, não poderiam mais ser objeto de sigilo e que a restrição de acesso a informações relativas à vida privada, honra e imagem de pessoas não poderia ser invocada em ações destinadas à recuperação de fatos históricos de maior relevância.

A Comissão Nacional da Verdade é igualmente fruto desse cenário marcado pelo compromisso do Estado brasileiro com o fortalecimento dos valores da democracia, a consolidação de uma cultura de defesa dos direitos humanos, o aprofundamento do processo de justiça de transição e o cumprimento de seu dever de memória e de assegurar o direito à verdade. É possível pensar o significado histórico da criação da CNV a partir do discurso proferido pela presidenta Dilma Vana Rousseff no ato da decretação da Lei de instituição da mesma: 
A Comissão da Verdade tem grande significado para o Brasil e para os brasileiros. O Congresso Nacional reconheceu isso, pois o projeto que hoje sancionamos foi apoiado por todos os partidos políticos com representação no Legislativo federal. Este apoio suprapartidário mostra que a Comissão significa, fundamentalmente, uma manifestação de respeito e um tributo aos que lutaram pela democracia no Brasil em qualquer época. [...] Isso lançará luzes sobre períodos da nossa história que a sociedade precisa e deve conhecer. São momentos difíceis que foram contados até hoje, ou, melhor dizendo, foram contados durante os acontecimentos sob um regime de censura, arbítrio e repressão, quando a própria liberdade de pensamento era proibida. [...] É fundamental que a população, sobretudo os jovens e as gerações futuras, conheçam nosso passado, principalmente o passado recente, quando muitas pessoas foram presas, foram torturadas e foram mortas. [...] Depois de passarem por períodos ditatoriais, vários países da América Latina tiveram suas comissões da verdade com nomes diferentes, com formas de atuação distintas. Houve experiências no Chile, na Argentina, no Peru, na África do Sul. Cada país fez do seu jeito e fez a seu tempo, segundo as suas próprias circunstâncias e sua própria história. O Brasil está fazendo agora. Este é o nosso momento histórico, esta é a nossa hora (BRASIL, 2011b).

Conforme se nota, a Comissão foi instalada com a finalidade de elucidar os fatos e as circunstancias das violações de direitos humanos praticadas pelo Estado brasileiro e seus agentes no período entre 18 de setembro de 1946 e 5 de outubro de 1988. Para tanto, é fundamental ressaltar que a simbiose entre a Lei de Acesso à Informação e a Comissão Nacional da Verdade foi crucial, na medida que os dispositivos jurídicos da LAl ofereceram respaldo nas situações concretas de recolhimento, produção e estruturação de um extenso acervo documental, escrito, imagético e oral pela CNV.

Os trabalhos da CNV foram norteados por objetivos bem definidos, quais sejam, promover o esclarecimento das circunstâncias e da autoria dos casos de torturas, mortes, desaparecimentos forçados e ocultação de cadáveres, além da identificação e a revelação pública de estruturas, locais, instituições e contextos relacionados à prática de violações de direitos humanos, incluindo suas eventuais ramificações nos diversos aparelhos estatais e na sociedade; encaminhar aos órgãos públicos competentes qualquer informação que pudesse auxiliar na localização e identificação de corpos e restos mortais de desaparecidos políticos; colaborar para apuração das violações e prestação de assistência às vítimas envolvidas; participar na adoção de medidas e políticas públicas de prevenção com vistas a não repetição dos crimes de Estado.

O método de trabalho da Comissão baseou-se na criação de 3 subcomissões: "Comunicação Externa", "Relações com a sociedade civil e instituições" e "Pesquisa, geração e sistematização das informações”. À subcomissão "Comunicação Externa" couberam tarefas como o relacionamento com a imprensa e os principais veículos de comunicação do país. À subcomissão "Relações com a sociedade civil e instituições", coube o relacionamento com 
entes públicos ${ }^{3}$, que, de alguma maneira, apoiaram os trabalhos da CNV, e a interlocução com o Ministério da Defesa e as Forças Armadas - ao mesmo tempo a mais difícil e mais relevante para o desempenho das funções legalmente atribuídas à Comissão. Essa comunicação se deu, basicamente, através do encaminhamento de pedidos de informação, da solicitação de abertura de sindicâncias para apurar o uso de instalações militares para possível prática de crimes e da convocação de reuniões de trabalho com objetivo de obter informações. No âmbito civil, o diálogo se deu pela realização de reuniões de trabalho com grupos de familiares de vítimas, para o planejamento de audiências e sessões públicas, depoimentos, atividades externas e acolhimento de denúncias, e com comitês populares de memória, verdade e justiça, que possuem mulheres e homens violados em seus quadros.

À subcomissão "Pesquisa, geração e sistematização das informações", coube a responsabilidade de organizar os trabalhos investigativos; analisar as fontes; constituir um núcleo pericial para investigar as circunstâncias das mortes das vítimas e também caracterizar locais e métodos de tortura, execução, desaparecimento forçado e ocultação de cadáveres; promover audiências públicas, a fim de ouvir relatos de vítimas e testemunhas, assim como depoimentos de agentes da repressão - atividade inteiramente respaldada pela Lei da CNV, que, em seu artigo $4^{\circ}$ inciso III, concedeu a prerrogativa de "convocar, para entrevistas ou testemunhos, pessoas que possam guardar qualquer relação com os fatos e circunstâncias examinados". Esta subcomissão ainda se comprometeu com a produção do relatório final dos trabalhos da CNV.

A metodologia da tomada de depoimentos da Comissão envolveu definir, primeiramente, as pessoas cuja oitiva seria interessante para as investigações. Nesse processo, a CNV contou com o apoio das comissões da verdade instaladas nos estados, municípios e universidades, assim como dos familiares de vítimas e dos comitês populares de memória, verdade e justiça, que indicaram possíveis depoentes. Depois, foram feitos levantamento de informações sobre cada pessoa a ser ouvida, em bases de dados públicos, e elaboração de roteiros de perguntas personalizados. As vítimas e as testemunhas das violações se apresentaram voluntariamente aos depoimentos ou foram convidadas a fazê-lo. Os agentes públicos, por seu turno, foram convocados por notificação encaminhada pelo Departamento

\footnotetext{
${ }^{3}$ Dentre tais, podem ser elencados a Casa Civil, a Secretaria-Geral da Presidência da República e a Secretaria de Comunicação Social; os ministérios da Justiça, da Educação, da Ciência, da Tecnologia e Inovação e das Relações Exteriores; a secretaria de Direitos Humanos e a de Políticas para as Mulheres; a AdvocaciaGeral da União; o Conselho Nacional de Justiça e o Conselho Nacional do Ministério Público; o Ministério Público Federal e o Ministério Público dos estados; o Arquivo Nacional e os diversos Arquivos Públicos estaduais; e o Departamento de Polícia Federal.
} 
de Polícia Federal (DPF), que teve incumbência de conduzir coercitivamente, na hipótese de objeção, e de instaurar inquérito policial, no caso de ausência.

A Comissão manteve o sigilo sobre as identidades quando isto era solicitado pelo depoente, sem, porém, deixar de tornar públicas as informações contidas nos testemunhos. Um instrumento usado nesses casos foram os formulários padrão disponibilizados no site da CNV, que poderiam ser enviados pelas próprias vítimas ou testemunhas das violações e também por comitês e outras comissões da verdade - também se respeitando o sigilo de identidade da vítima ou testemunha, uma vez que fosse solicitado.

A iniciativa da gestão Dilma Vana Rousseff de criar um espaço legitimado pelo Estado para ouvir os relatos de vítimas, testemunhas e algozes da ditadura militar representou uma ferramenta efetiva de desestabilização no pacto com o silêncio instituído pelo regime autoritário e, até então, tolerado pelos governos democráticos. A institucionalização de novos espaços de lembrar, produzir outras narrativas e deixar vir à tona memórias subterrâneas traumáticas, no Brasil, acompanha um movimento que ganha expressão no mundo ocidental a partir das últimas décadas do século XX, quando, segundo Giensen (2001, p. 216, tradução nossa), "ao invés de se louvarem os heróis fundadores de uma comunidade, os monumentos e rituais públicos recordam o sofrimento das vítimas e os crimes dos perpetradores".

\section{Considerações finais}

No curso deste artigo, objetivou-se discutir o extenso caminho de disputas jurídicopolíticas acerca do legado da ditadura militar no Brasil, as quais impactaram diretamente a garantia de direitos humanos básicos no país, como o direito à informação, à memória e à verdade, além da própria investigação historiográfica deste período obscurecido. Procurouse mostrar que a Lei de Anistia, uma espécie de anomalia jurídica promotora de um bloqueio institucional, não apenas consagrou a impunidade dos crimes cometidos pelos agentes do Estado militar, mas contribuiu para fortalecer a privatização da memória e da verdade imposta pelas Forças Armadas.

Buscou-se demonstrar de que maneira o excesso de controle castrense no pacto transicional produziu um sistema democrático outorgado, marcado pelo esquecimento e alheamento da sociedade civil em relação aos eventos de sua história traumática, pela homogeneização da memória do período ditatorial através da construção de uma memória 
“oficial”, pelo silenciamento das memórias incômodas, pela omissão em relação aos arquivos sensíveis do período, pelo atraso no estabelecimento da justiça de transição no país, e, finalmente, pela sensação de que a ditadura é um fenômeno inacabado.

Salientou-se que este mecanismo político permaneceu operando nos primeiros governos democráticos da Nova República, na década de 1990, apesar de alguns passos meritório - porém, limitados - terem sido dados na gestão de Fernando Collor de Mello e de Fernando Henrique Cardoso, como a aprovação da Lei da Política Nacional de Arquivos, da Lei dos desaparecidos, da Lei da Tortura e a criação da Comissão de Anistia para, entre outros fins, promover reparações pecuniárias. A Lei de Anistia ainda continuou atuando de modo a constranger institucionalmente a ação das novas lideranças políticas, que acabavam por se acomodar e aderir ao paradigma da manutenção do silêncio como prerrogativa para a segurança da nascente democracia nacional, ao invés de promover rupturas em favor da justiça de transição.

Almejou-se evidenciar que o Estado democrático brasileiro paulatinamente assumiu compromisso com seu dever de memória e papel de garantidor de direitos humanos fundamentais a partir dos governos de Luiz Inácio Lula da Silva e Dilma Vana Rousseff, nos anos 2000. Observou-se, durante tais administrações, uma clara transformação no perfil do Estado enquanto ator político, passando de detentor de memórias privatizadas e violador dos direitos humanos a promotor de memórias coletivas e direitos humanos. Em tal sentido, as medidas em favor do direito à informação, como o recolhimento dos acervos da ditadura junto ao Arquivo Nacional, a criação do Memórias Reveladas e a instituição da Lei de Acesso à Informação, atuaram como instrumentos na promoção e aplicação de outros direitos fundamentais, como o direito à memória e à verdade histórica.

Procurou-se demonstrar que outra medida vital para a desprivatização da memória e a deselitização dos direitos humanos no pais foi a criação da Comissão Nacional da Verdade, que provocou uma descontinuidade na proibição de se lembrar o passado e possibilitou a emergência do ausente negado, silenciado, não-dito. O testemunho, meio efetivo de trazer à tona a memória silenciada, subterrânea e suprimida pela memória "oficial", intencionalmente produzida, permitiu que esta fosse repensada, contextualizada, criticada e historicizada. Resgatar as memórias, tornar os fatos públicos, denunciar as atrocidades, apontar os responsáveis e trazer as violações ao conhecimento geral foram ações da CNV que possuíram papel político e simbólico substancial, tanto na construção de um novo pacto na 
sociedade brasileira após a experimentação traumática do regime militar, quanto na produção de significados coletivos mais verdadeiros acerca de sua memória e história.

\section{Fontes}

ANISTIA INTERNACIONAL. Eles nos tratam como animais - Tortura e maus tratos no Brasil: desumanização e impunidade no sistema da Justiça Criminal. Londres: Anistia Internacional, 2001.

ASSEMBLEIA GERAL DA ONU. Declaração Universal dos Direitos Humanos. Paris: Nações Unidas, 1948.

BRASIL. Presidência da República. Casa Civil. Subchefia para Assuntos Jurídicos. Lei $n^{\circ}$ 8.159, de 8 de janeiro de 1991. Dispõe sobre a política nacional de arquivos públicos e privados e dá outras providências. 1991. Disponível em: http://www.planalto.gov.br/ccivil_03/LEIS/L8159.htm. Acesso em: 6 jan. 2020.

BRASIL. Presidência da República. Casa Civil. Subchefia para Assuntos Jurídicos. Lei $n^{\circ}$ 9.140, de 4 de dezembro de 1995. Reconhece como mortas pessoas desaparecidas em razão de participação, ou acusação de participação, em atividades políticas, no período de 2 de setembro de 1961 a 15 de agosto de 1979, e dá outras providências. 1995. Disponível em: http://www.planalto.gov.br/ccivil_03/LEIS/L9140.htm. Acesso em: 6 jan. 2020.

BRASIL. Presidência da República. Casa Civil. Subchefia para Assuntos Jurídicos. Lei $n^{\circ}$ 9.455, de 7 de abril de 1997. Define os crimes de tortura e dá outras providências. 1997. Disponível em: http://www.planalto.gov.br/ccivil_03/leis//9455.htm. Acesso em: 6 jan. 2020.

BRASIL. Presidência da República. Casa Civil. Subchefia para Assuntos Jurídicos. Constituição da República Federativa do Brasil de 1988. 1988. Disponível em: http://www.planalto.gov.br/ccivil_03/constituicao/constituicao.htm. Acesso em: 12 fev. 2020.

BRASIL. Presidência da República. Casa Civil. Subchefia para Assuntos Jurídicos. Decreto $n^{\circ}$ 4.553, de 27 de dezembro de 2002. Dispõe sobre a salvaguarda de dados, informações, documentos e materiais sigilosos de interesse da segurança da sociedade e do Estado, no âmbito da Administração Pública Federal, e dá outras providências. 2002. Revogado pelo Decreto $\mathrm{n}^{\circ}$ 7.845, de 14 de novembro de 2012. Disponível em: http://www.planalto.gov.br/ccivil_03/decreto/2002/D4553.htm. Acesso em: 6 jan. 2020.

BRASIL. Presidência da República. Casa Civil. Subchefia para Assuntos Jurídicos. Decreto $n^{\circ}$ 5.301, de 9 de dezembro de 2004. Regulamenta o disposto na Medida Provisória no 228, de 9 de dezembro de 2004, que dispõe sobre a ressalva prevista na parte final do disposto no inciso XXXIII do art. 5o da Constituição, e dá outras providências. 2004. Disponível em: http://www.planalto.gov.br/ccivil_03/_Ato2004-2006/2004/Decreto/D5301.htm. Acesso em: 6 jan. 2020.

BRASIL. Presidência da República. Casa Civil. Subchefia para Assuntos Jurídicos. Lei $n^{\circ}$ 11.111, de 5 de maio de 2005. Regulamenta a parte final do disposto no inciso XXXIII do caput do art. $5^{\circ}$ da Constituição Federal e dá outras providências. 2005. Disponível em: 
http://www.planalto.gov.br/ccivil_03/_Ato2004-2006/2005/Lei/L11111.htm. Acesso em: 6 jan. 2020.

BRASIL. Presidência da República. Casa Civil. Subchefia para Assuntos Jurídicos. Lei $n^{\circ}$ 12.527, de 18 de novembro de 2011. Regula o acesso a informações previsto no inciso XXXIII do art. $5^{\circ}$, no inciso II do § 30 do art. 37 e no $\S 2$ o do art. 216 da Constituição Federal; altera a Lei no 8.112, de 11 de dezembro de 1990; revoga a Lei no 11.111, de 5 de maio de 2005, e dispositivos da Lei no 8.159, de 8 de janeiro de 1991; e dá outras providências. 2011a.

Disponível

em: http://www.memoriasreveladas.gov.br/administrator/components/com_simplefilemanager/ uploads/582f414dc6b556.85202508/lei_12527.pdf. Acesso em: 6 jan. 2020.

BRASIL. Biblioteca Presidência da República. 18-11-2011 - Discurso da Presidenta da República, Dilma Rousseff, durante cerimônia de sanção do projeto de Lei que garante o acesso a informações públicas e do projeto de Lei que cria a Comissão Nacional da Verdade. 2011b. Disponível em: http://www.biblioteca.presidencia.gov.br/presidencia/expresidentes/dilma-rousseff/discursos. Acesso em: 12 fev. 2020.

BRASIL. Presidência da República. Casa Civil. Subchefia para Assuntos Jurídicos. Lei $n^{\circ}$ 12.528, de 18 de novembro de 2011. Cria a Comissão Nacional da Verdade no âmbito da Casa Civil da Presidência da República. 2011c. Disponível em: http://www.memoriasreveladas.gov.br/administrator/components/com_simplefilemanager/ uploads/582f40b1006ff9.04274490/lei_12528.pdf. Acesso em: 6 jan. 2020.

LEIA a íntegra da nota divulgada pelo Exército. Folha de S. Paulo, 19 out. 2004. Disponível em: https://www1.folha.uol.com.br/fsp/brasil/fc1910200417.htm. Acesso em: 28 dez. 2019.

QUEIMA de arquivo. G1, 13 dez. 2004. Disponível em: http://g1.globo.com/jornaldaglobo/0,,MUL894571-16021,00-QUEIMA+DE+ARQUIVO.html. Acesso em 28 dez. 2019.

\section{Referências}

ARENDT, Hannah. Entre o passado e o futuro. 7. ed. São Paulo: Perspectiva, 2013.

BATISTA, Carmem Lúcia. Informação pública: controle, segredo e direito de acesso. Intexto, Porto Alegre, n. 26, p. 204-222, jul. 2012. Disponível em: https://seer.ufrgs.br/intexto/article/view/19582. Acesso em: 12 fev. 2020.

BAUER, Caroline Silveira. Brasil e Argentina: ditaduras, desaparecimentos e políticas de memória. Porto Alegre: Medianiz, 2012.

BOBBIO, Noberto. A era dos direitos. Rio de Janeiro: Campus, 1992.

CALDERONI, Vivian; JESUS, Maria Gorete Marques de (Coord.). Julgando a tortura: análise de jurisprudência nos tribunais de justiça do Brasil (2005 - 2010). São Paulo: ACATBrasil/Conectas/NEV-USP/IBCCRIM/Pastoral Carcerária, 2015. 
CAMARGO, Alessandra Lopes. O dever de memória do Estado no processo de justiça de transição no Brasil. Idéias - Rev. Inst. Filos. Ciênc. Hum., v. 7, n. 1, p. 249-270, jan./jul. 2016. https://doi.org/10.20396/ideias.v7i1.8649519

CATELA, Ludmila da Silva. Do segredo à verdade. Processos sociais e políticos na abertura dos arquivos da repressão no Brasil e na Argentina. IN: TELES, Janaina; TELES, Edson; SANTOS, Cecilia M. (Org.). Desarquivando a ditadura: memória e justiça no Brasil. São Paulo: Hucitec, 2009. p. 444-471.

COMPARATO, Fábio Konder. A tortura no direito internacional. Brasília: SEDH/Coordenação Geral de Combate à Tortura, 2010. v. 1.

D'ARAUJO, Maria Celina de. A elite dirigente do governo Lula. Rio de Janeiro: CPDOC, 2009.

ANGELO, Vitor Amorim de. Quem tem documentos sobre a ditadura? Uma análise da legislação e das iniciativas governamentais. Política \& Sociedade, v. 11, n. 21, p. 199-234, 2012. https://doi.org/10.5007/2175-7984.2012v11n21p199

FICO, Carlos. Como eles agiam: os subterrâneos da ditadura militar: espionagem e polícia política. Rio de Janeiro: Record, 2001.

FICO, Carlos. História do Tempo Presente, eventos traumáticos e documentos sensíveis. O caso brasileiro. Varia história, v. 28, n. 47, p. 43-59, jan./jun. 2012. https://doi.org/10.1590/S0104-87752012000100003

FÉLIX, Jorge Armando. Herança militar. Folha de São Paulo, São Paulo, p. 4, 14 nov. 2004. Entrevista concedida a Eliane Castanhéde.

FURTADO, Eliana; RAMALHO, Lúcia. A política de acesso do Aperj ao acervo Dops. Arquivo \& História, n.3, p. 49-76, 1997.

GAGNEBIN, Jeanne Marie. O preço de uma reconciliação extorquida. In: TELES, Edson; SAFATLE, Vladimir. (Org.). O que resta da ditadura. São Paulo: Boitempo, 2010. p. 177186.

GIDDENS, Anthony. O Estado-nação e a violência: segundo volume de uma crítica contemporânea ao materialismo histórico (1985). São Paulo: Edusp, 2001.

GIENSEN, Bernard. Sobre héroes, víctimas y perpetradores. Puentes, Buenos Aires, ano 2, n. 5, p. 14-24, 2001.

HEYMANN, Luciana Quillet. O "devoir de mémoire" na França contemporânea: entre a memória, história, legislação e direitos. In: GOMES, Â. de C. (Org.). Direitos e cidadania: memória, política e cultura. Rio de Janeiro: FGV, 2007. p. 1-26.

JARDIM, José Maria. A lei de acesso à informação pública: dimensões políticoinformacionais. In: ENCONTRO NACIONAL DE PESQUISA EM CIÊNCIA DA INFORMAÇÃO, 13., 2012, Rio de Janeiro. Anais... Rio de Janeiro: FIOCRUZ, 2012. p. 121. 
MEZAROBBA, Glenda. Um acerto de contas com o futuro: a anistia e suas consequências - um estudo do caso brasileiro. 2003. Dissertação (Mestrado) - Faculdade de Filosofia, Letras e Ciências Humanas, Universidade de São Paulo, São Paulo, 2003.

MOTTA, Rodrigo Patto Sá (Org.). Culturas políticas na história: novos estudos. Belo Horizonte: Argumentum/FAPEMIG, 2009.

NAPOLITANO, Marcos. 1964: história do regime militar brasileiro. São Paulo: Contexto, 2014.

PAES, Eneida Bastos. A construção da lei de acesso à informação pública no Brasil: desafios na implementação de seus princípios. Revista do Serviço Público, v. 62, n. 4, p. 407-423, 2011. https://doi.org/10.21874/rsp.v62i4.80

PIMENTA, João Paulo Garrido. Os arquivos do DEOPS-SP: nota preliminar. Revista de História, São Paulo, v. 132, p. 149-154, 1995.

POLLAK, Michael. Memória, esquecimento, silêncio. Estudos Históricos, Rio de Janeiro, v. 2, n. 3, p. 3-15, 1989.

QUADRAT, Samantha Viz. Em busca dos arquivos das ditaduras do Cone Sul: desafios e perspectivas. In: ARAUJO, Maria Paula; FICO, Carlos; GRIN, Monica (Ed.). Violência na História: memória, trauma e reparação. Rio de Janeiro: Ponteio, 2013. p. 56-79.

RICOEUR, Paul. Memory, history, oblivion. Palestra proferida na Conferência Internacional "Haunting Memories? History in Europe after Authoritarianism”. Budapeste: [s.n.], 2003.

RICOEUR, Paul. A memória, a história, o esquecimento. Campinas: Unicamp, 2007.

SANTOS, Shana Marques Prado dos. Tratamento de arquivo de direitos humanos na América. Brasília: Ministério da Justiça, Comissão de Anistia, Rede Latino-Americana de Justiça de Transição (RLAJT), 2016.

TORELLY, Marcelo D. Justiça Transicional, memória social e senso comum democrático: notas conceituais e contextualização do caso brasileiro. In: SANTOS, Boaventura de Sousa et al. (Org.). Repressão e memória política no contexto ibero-brasileiro: estudos sobre Brasil, Guatemala, Moçambique, Peru e Portugal. Brasília: Ministério da Justiça, Comissão de Anistia; Portugal: Universidade de Coimbra, 2010. p. 104-123. 